\title{
PLATELET-RICH PLASMA APPLICATIONS IN MOLAR RETENTION AND DENTAL CYST SURGERY
}

\author{
Stelian Edrev, Ivan Gonkov \\ Department of Oral and Maxillofacial Surgery, Faculty of Dental Medicine, \\ Medical University of Varna
}

\begin{abstract}
INTRODUCTION: Dental retentions and cysts are common pathology necessitating proper surgical treatment. During the recent decade, platelet-rich plasma has increasingly been used in oral surgery.

AIM: Our aim was to illustrate its application alone and in combination with autologous bone or collagen in patients after odontectomy for dental retenion and cystectomy for dental cysts.

MATERIALS AND METHODS: A total of 53 patients, 28 males and 23 females, with retained molars or dental cysts were diagnosed and surgically treated between May 2017 and May 2019. Odontectomy was carried out in 36 pateints and cystectomy - in 21 ones. According to an original protocol of platelet-rich plasma preparation, it was applied alone in 21 , along with autologous bone - in 14, and combined with collagen - in 19 patients.
\end{abstract}

RESULTS AND DISCUSSION: The comparison with a sex- and age-matched control group without such applications demonstrated certain advantages in terms of the positive effects of platelet-rich plasma on wound healing, pain perception and bone regeneration.

CONCLUSION: Further research is needed to more comprehensively assess the benefits of these growth factors in oral surgery.

Keywords: molar retention, radicular cysts, oral surgery, platelet-rich plasma, autologous bone, collagen

Address for correspondence:

Stelian Edrev

Department of Oral and Maxillofacial Surgery

Faculty of Dental Medicine

Medical University of Varna

84 Tsar Osvoboditel Blvd

BG-9002 Varna, Bulgaria

e-mail: stelian.edrev@mu-varna.bg

Received: May 4, 2019

Accepted: June 18, 2019

\section{INTRODUCTION}

Dental retentions are highly prevalent among the general population and their removal can involve multiple complications (1). The surgeon's detailed anatomical knowledge of the operated region proves crucial for the surgery outcome $(2,3,4)$. Platelet-rich plasma application is proposed in an attempt to avoid these complications, as it contains numerous growth factors and stimulates diverse biological functions that facilitate the healing of soft and hard tissues. 
Platelet-rich plasma is used in a variety of clinical situations in the field of oral surgery, e.g, in the post-extraction alveoli of retained lower third molars $(1,5,6)$.

Platelet-rich plasma application reduces pain and inflammation, accelerates the epithelialization of soft tissues and promotes bone regeneration (7). When applied to the periodontal pocket, platelet-rich plasma exerts an anti-inflammatory therapeutic effect in 20 chronic periodontitis patients (8).

Combined use of platelet-rich plasma and bovine-derived hydroxyapatite graft materials for the treatment of intrabony defects of the fully impacted mandibular second molars following their surgical extraction provides early bone regeneration (9).

\section{AIM}

The purpose of the present study is to describe our method for therapeutic application of plateletrich plasma alone as well as in combination with ei- that of the male and female patients was 33.32 years (range, 14-68) and 30.80 years (range, 18-58), respectively. Fifty-three sex-matched patients in the control group (without any platelet-rich plasma application) were at a mean age of 31.30 years (range, 15-70). Males were aged 29.21 years (range, 15-70) on average and females - 30.84 years (range, 19-53) on average. It was noteworthy that $50 \%$ of the males and $60 \%$ of the females were aged $\leq 30$ years as evidence of the social significance of this pathology.

Odontectomy was performed for mandibular and maxillary impacted molars but cystectomy was done for radicular cysts according to a routine oral surgical protocol.

Male and female patients' distribution according to the diagnosis and the kind of platelet-rich plasma application (alone, in combination with autologous bone, and with collagen) is demonstrated in Table 1 .

Table 1. Platelet-rich plasma applications in patients with retained molars and radicular cysts

\begin{tabular}{|l|c|c|c|c|c|c|c|}
\hline \multirow{2}{*}{ Diagnosis } & \multicolumn{2}{|c|}{ PRP Alone } & \multicolumn{2}{c|}{ PRP+Bone } & \multicolumn{2}{c|}{ PRP+Collagen } \\
\cline { 2 - 8 } & Males & Females & Males & Females & Males & Females & Total \\
\hline Single retained molar & 5 & 4 & 4 & 2 & 5 & 4 & 24 \\
\hline Single reticular cyst & 5 & 1 & - & 4 & 5 & - & 15 \\
\hline Two retained molars & - & 4 & - & 2 & - & 2 & 8 \\
\hline One molar and two cysts & 1 & - & - & 1 & 1 & - & 3 \\
\hline Two reticular cysts & - & - & - & - & 2 & - & 2 \\
\hline Four retained molars & - & - & 1 & - & - & - & 1 \\
\hline Three reticular cysts & 1 & - & - & - & - & - & 1 \\
\hline \multirow{2}{*}{ total } & 12 & 9 & 5 & 9 & 13 & 6 & $54^{*}$ \\
\hline
\end{tabular}

PRP - protein-rich plasma

${ }^{\star}$ In one patient, two consecutive surgical interventions were performed.

ther autologous bone or collagen in patients with dental retenion and dental cysts.

\section{MATERIALS AND METHODS}

Our study covered a total of 53 randomly selected patients, 28 males and 23 females, with retained molars or dental cysts diagnosed and surgically treated in the Department of Oral and Maxillofacial Surgery of the Medical University of Varna during the period from May 2017 to May 2019. The mean age of the whole group was 32.13 years (range, 14-68) and

\section{Protocol for Platelet-Rich Plasma Production}

Fifteen $\mathrm{mL}$ of a patient's blood were added to a mixture of $1 \mathrm{~mL}$ of citrate, phosphate, dextrose and alanine in two sterile containers. Twofold blood centrifugation was done. The first procedure was performed at $2400 \mathrm{rev} / \mathrm{min}$. for $10 \mathrm{~min}$. in order to separate erythtrocytes from plasma (Fig. 1). Supernatant plasma was put by using sterile pipette into new sterile test tubes for the second centrifugation at 3600 rev/min. for $15 \mathrm{~min}$. in order to concentrate plate- 
lets in a platelet-rich plasma (Fig. 2). The latter was at the bottom of the test tube as a 10-percent fraction while the rest of the plasma was considered plateletpoor plasma. To the platelet-rich plasma separated from the platelet-poor one by using sterile pipette, 1 $\mathrm{mL}$ of $10 \%$ of a calcium dichloride solution was added in order to activate the platelet-rich plasma. Collagen addition to the platelet-rich plasma is shown on Fig. 3 and autologous bone preparation is displayed on Fig. 4. The favourable effects on bone regeneration of these platelet-rich plasma applications during different intervals after surgery were comparatively assessed between both groups.

\section{RESULTS}

Odontectomies and cystectomies were performed in 36 and 21 patients, respectively. Plateletrich plasma in combination with autologous bone was applied more frequently in females while in combination with collagen - in males.

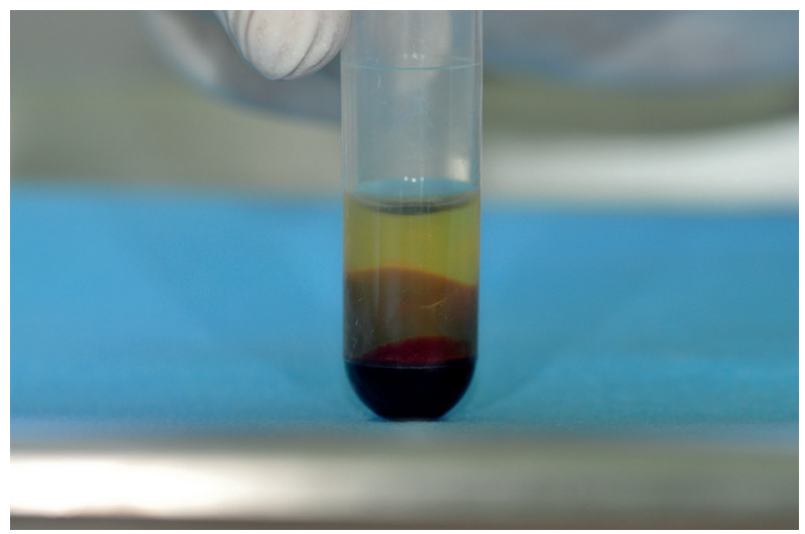

Fig. 1. Separation of plasma from erythrocytes after the first centrifugation

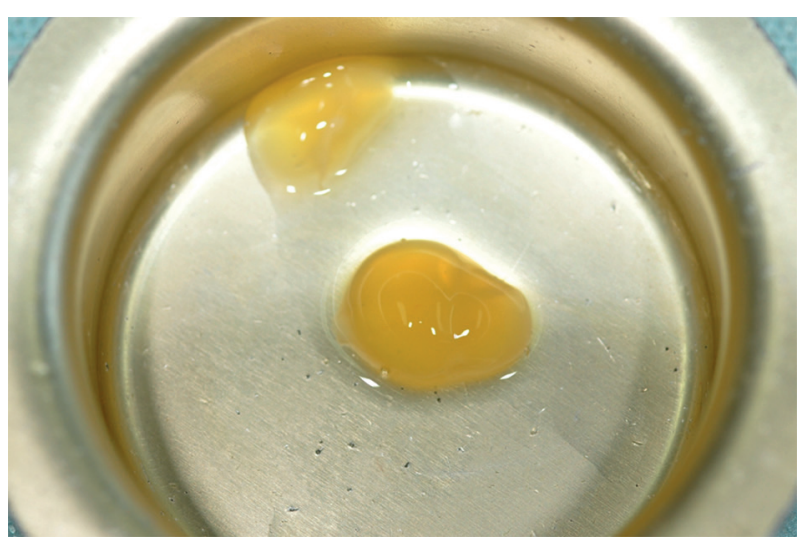

Fig. 2. Pure platelet-rich plasma

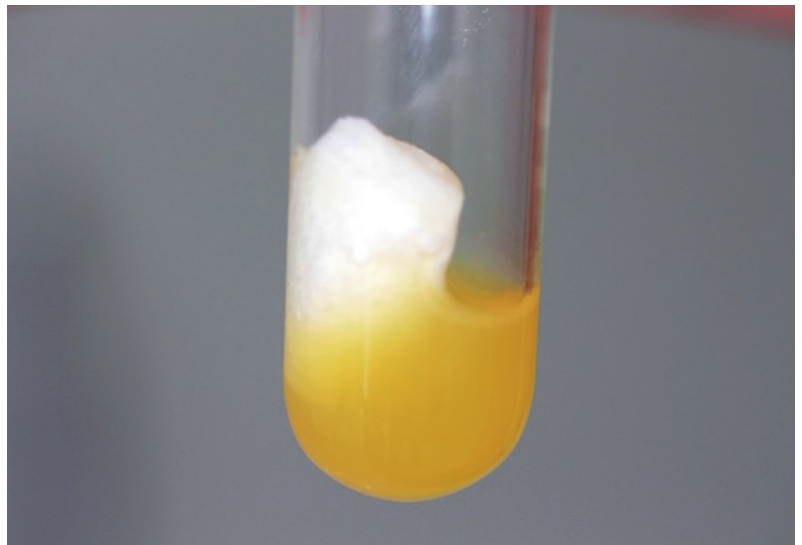

Fig. 3. Collagen addition to platelet-rich plasma

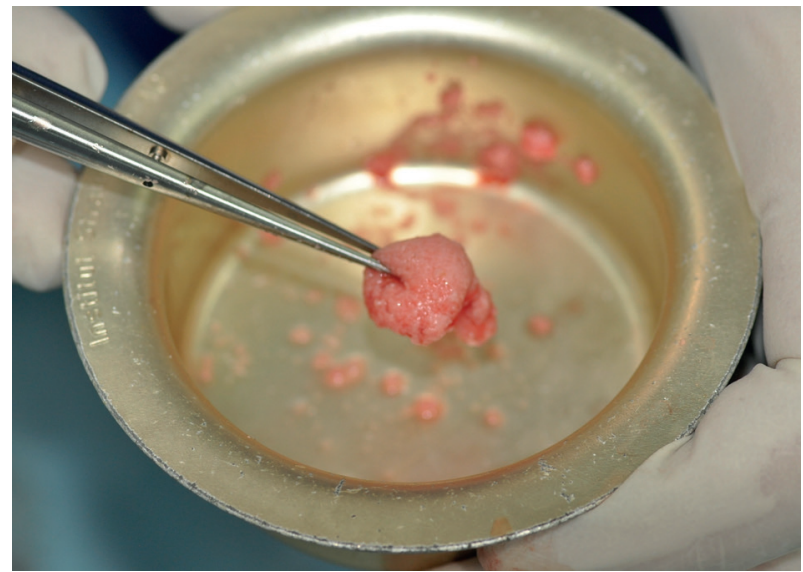

Fig. 4. Autologous bone prior to placement

Bone defects immediately after odontectomy and cystectomy are indicated on Fig. 5 and Fig. 6.

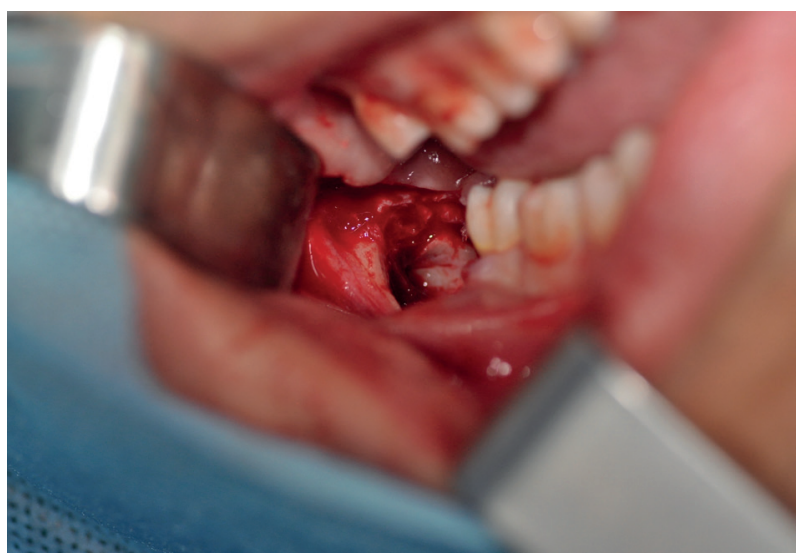

Fig. 5. Bone defect after odontectomy

Placements of platelet-rich plasma alone and with autologous bone into the osseous defects are demonstrated on Fig. 7 and Fig. 8. 


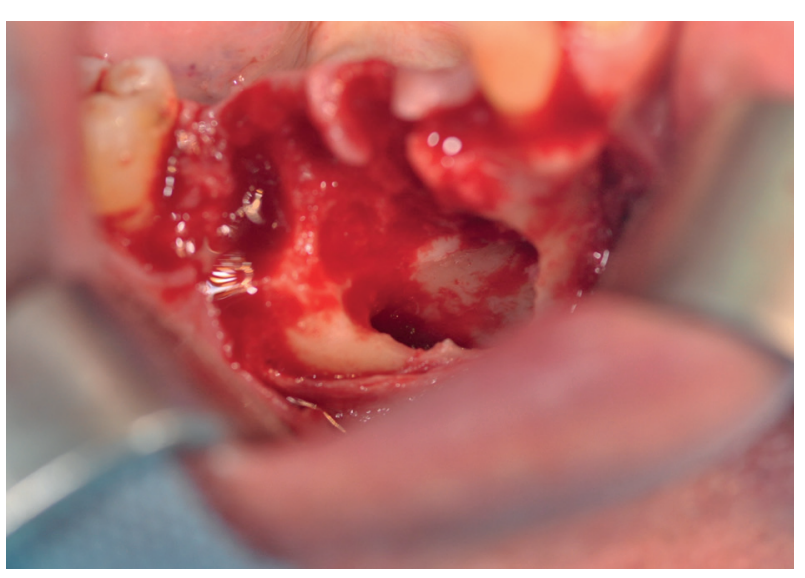

Fig. 6. Bone defect after cystic sack extirpation

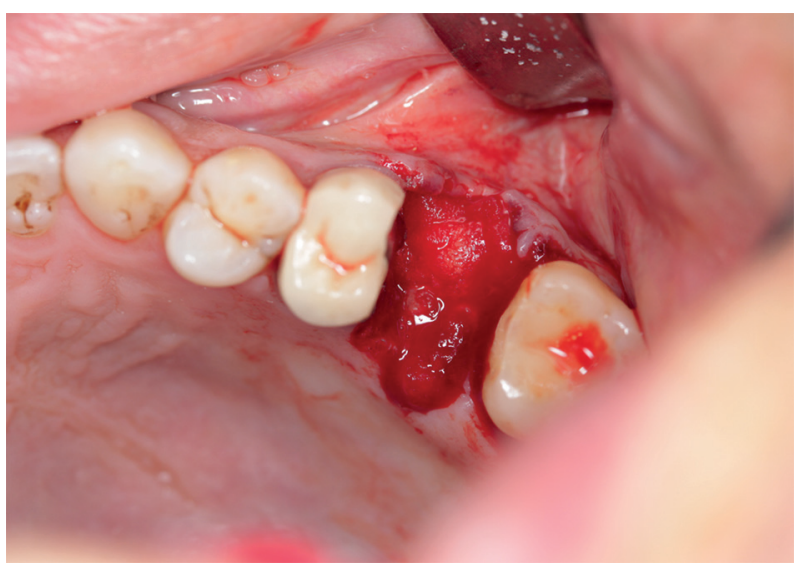

Fig. 7. Platelet-rich plasma placement into the osseous defect

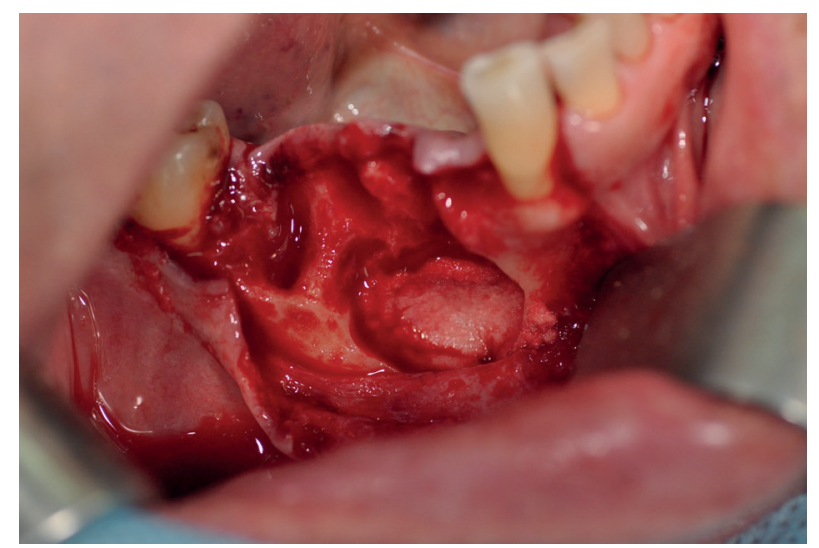

Fig. 8. Placement of platelet-rich plasma with autologous bone into the osseous defect

Our results demonstrate certain advantages of the platelet-rich plasma applications in the patients with dental retention and cysts in terms of pain perception and bone density. However, because of the relatively small sample of ours, they remain statistically insignificant ( $\mathrm{p}>0.05)$.

\section{DISCUSSION}

Our results are similar to those reported in the foreign scientific literature.

A new technique for odontectomy of deeply impacted mandibular third molars using computerguided cutting to maintain inferior alveolar nerve integrity and the covering buccal bone is positively evaluated (10).

Recently, the interest in the applications of variety of products containing growth factors in oral surgery has gradually increased.

Within a single-site, randomized-controlled investigation of the clinical and histologic outcome of using medical-grade calcium sulfate hemihydrate mixed with platelet-rich plasma for extraction socket preservation graft before implant placement it is proved that there is greater vital bone volume at three months with rapid enhancement of bone healing compared to platelet-rich plasma-free collagen resorbable graft (11).

Healing of platelet-rich plasma-treated mandibular and maxillary molar sockets differs statistically significantly from that of control sockets at one-, three-, and six-month follow-up and provides a safe and effective means of speeding alveolar bone repair and new bone formation following impacted third molar extraction (12). Autologous platelet-rich plasma applied in tooth sockets after extractions of bilateral impacted mandibular third molars accelerates alveolar bone regeneration and ensures a better repair in men than in women $(13,14)$.

Nowadays platelet-rich fibrin is relatively commonly used during lower third molar extractions. A meta-analysis of 10 studies retrieved from PubMed, Web of Science, EMBASE, and the Cochrane Library and including 468 cases of platelet-rich fibrin application and 467 cases of non-platelet-rich fibrin one demonstrates that platelet-rich fibrin statistically significantly relieves pain $(\mathrm{p}=0.01)$ and three-day postoperative swelling $(\mathrm{p}=0.03)$ as well as reduces alveolar osteitis incidence rate $(\mathrm{p}<0.0001)(15)$. Another meta-analysis of randomized clinical trials dealing with alveolar osteitis concludes that platelet-rich fibrin accelerates healing in mandibular third molar surgery by reducing postoperative pain and swelling 
and reduces alveolar osteitis prevalence rate as well (16). There is markedly greater bone formation in bilaterally impacted mandibular third molar sockets as well as a better osseous regeneration and soft tissue healing aftwr treatment with platelet-rich fibrin (17). Autologous platelet-rich fibrin application lessens the severity of immediate postoperative sequelae, decreases preoperative pocket depth, and hastens bone formation in mandibular third molar extraction sockets (18).

Among 5294 cases of jaw cysts diagnosed during a 38-year period, radicular cysts are most common followed by dentigerous, residual, and odontogenic keratocysts (19). During the period from January 2001 to December 2016 in Southern Taiwan, 232 patients, 133 females and 99 males at a mean age of 40.5 years (range, 13-78 with radicular cysts are diagnosed (20). Some 201 cysts occur in the maxilla $(86.64 \%)$ and 31 ones - in the mandible $(13.36 \%$ of the cases).

According to data from 16 studies, the prevalence of odontogenic cysts associated with impacted third molars is $4.4 \%$ (between 2.5 and $6.8 \%$ at $95 \%$ confidence interval) (21). The dentigerous cyst is mentioned in eleven studies with a pooled prevalence of $2.1 \%$ (between 1.4 and $3.1 \%$ at $95 \%$ confidence interval), the radicular cyst - in three studies and with a prevalence of $4.7 \%$ (between 0.0 and $19.4 \%$ at $95 \%$ confidence interval) and the odontogenic keratocyst - in nine studies and with a prevalence of $0.5 \%$ (between 0.2 and $0.7 \%$ at $95 \%$ confidence interval).

Among 7259 biopsy records of elderly patients from four Brazilian referral centres between 2000 and 2016, there are 491 odontogenic (76.5\%) and 76 non-odontogenic cysts (11.8\%) (22). There are 268 radicular and 21 salivary duct cysts. Among 2114 biopsy records of Brazilian children between 1980 and 2016, there are 294 odontogenic (76.5\%) and 16 nonodontogenic cysts (11.8\%) (23). There are 145 radicular and four epidermoid cysts. During a 10 -year period, a total of 526 cysts are diagnosed in 330 males and in 196 females in Ataturk University, Eastern Turkey (24). There are 509 odontogenic and 17 nonodontogenic cysts, mainly radicular (66.4\%), dentigerous $(19.2 \%)$ and residual (10.8\%) cysts.

In a randomized prospective comparative study of 20 patients with periapical osseous jaw defects, use of platelet-rich plasma combined with calcium sulfate and autologous bone graft results in a better bone regeneration (25). The results of a prospective, randomized trial in 67 healthy children aged 8-11 years with 88 immature necrotic incisors demonstrate that the applications of platelet-rich plasma, platelet-rich fibrin, a platelet pellet and an induced blot clot are effective in regenerative endodontic procedures (26). Autologous platelet concentrates including platelet-rich plasma, platelet-rich fibrin and plasma rich in growth factors used following tooth extraction improve soft tissue healing, probing depth and bone density, as well as reduce swelling and trismus (27). According to a meta-analysis of the 222 immature permanent teeth, platelet-rich plasma and platelet-rich fibrin induce more effectively apical closure than blood-clot revascularization for the regeneration of these teeth (28).

The comparative investigation of autologous bone, platelet-rich plasma and two biomaterials such as synthetic calcium hydroxyapatite and demineralized bone matrix proves that autologous bone is the gold standard material for alveolar bone regeneration after impacted mandibular third molar extraction (29). Within a prospective, randomized, singleblind split-mouth study, the application of an alloplastic bone graft (collagen and hydroxyapatite) following surgical removal of bilateral impacted mandibular third molars results in an alveolar bone level increase, probing depth improvement, and better wound healing and prevents the periodontal defects distal to mandibular second molars (30).

Pure type-1 collagen aplication to the third molar extraction socket can reduce post-operative pain score and duration, decrease the frequency of mouthopening limitation, and increase mineralization ratio at the extraction socket site (31). Collagen membranes promote wound healing through isolation, clot stabilization, wound stability, and hemostasis, enhance primary wound coverage through their chemotactic ability to attract fibroblasts, and augment flap thickness by providing a collagenous scaffold after partially impacted mandibular third molar surgery (32). The resorbable collagen membranes after surgical extraction of mesioangular or horizontally impacted lower third molar stimulates bone regeneration by improving the attachment level and bone fill 
distal to the lower second molar, decreases the distal probing depth and results in faster recovery (33).

In a 10 -year-old girl presenting with a large radicular cyst associated with neglected carious mandibular deciduous second molar, a successful surgical management using autologous platelet-rich fibrin augmentation results in accelerated healing of the bone defect (34). A 20-year-old female presenting with forced root-filling material outside the root canal of $45^{\text {th }}$ tooth reaching the radicular cyst around the root and the mandibular canal is successfully treated by means of timely cystectomy and filling material removal (35).

\section{CONCLUSION}

Our preliminary resuls encourage us to further investigate the beneficial effects of these growth-factor containing platelet-rich plasma applications in oral surgery.

\section{REFERENCES}

1. Barona-Dorado C, González-Regueiro I, MartínAres M, Arias-Irimia O, Martínez-González JM. Efficacy of platelet-rich plasma applied to post-extraction retained lower third molar alveoli. A systematic review. Med Oral Patol Oral Cir Bucal. 2014;19(2):e142-8. doi: 10.4317/medoral.19444.

2. Tihomir Georgiev, Stefan Peev, Hristina Arnautska, Albena Gencheva, Ivan Gerdzhikov An Evaluation of Three-Dimensional Scans of the Time-Dependent Volume Changes in Bone Grafting Materials, International Journal of Science and Research (IJSR) ISSN (Online): 2319-7064, p. 562-571

3. Tihomir Georgiev, Stefan Peev, Mariana Dimova Changes in X-ray image of the maxillary sinus mucosa near endodontic treated teeth with and without visible clinical manifestations of pathological processes. Dental Review, March 2016, 5-9, ISSN: 1313-4655

4. Georgiev T., Peev St., Arnautska Hr., Prodanova Kr., Dimova M. Preoperative study of the vestibular wall of the maxillary sinus with a cone-beam computer tomograph before sinuslift. Dental Review, March 2016, 97-101, ISSN: 1313-4655

5. Stefan Peev, Borislav Ivanov, Elitsa Sabeva, Tihomir Georgiev Five-year follow-up of implants placed simultaneously with inferior alveolar nerve lateralisation or transposition Scripta Scientifica Medicinae Dentalis, vol. 1, №2, 2015, pp. 44-48
6. Stefan Peev, Elitsa Sabeva, Angela Gusiyska, Tihomir Georgiev, Tsvetan Tonchev Long-term follow-up of implants with reduced length Scripta Scientifica Medicinae Dentalis, vol. 1, №2, 2015, pp. 49-52

7. Anitua E, Tejero R, Zalduendo MM, Orive G. Plasma rich in growth factors promotes bone tissue regeneration by stimulating proliferation, migration, and autocrine secretion in primary human osteoblasts. J Periodontol. 2013;84(8):1180-1190. doi: 10.1902/jop.2012.120292.

8. Abdul Ameer LA, Raheem ZJ, Abdulrazaq SS, Ali BG, Nasser MM, Aldeen Khairi AW. The anti-inflammatory effect of the platelet-rich plasma in the periodontal pocket. Eur J Dent. 2018;12(4):528-531. doi: 10.4103/ejd.ejd_49_18.

9. DurmuŞlar MC, Alpaslan C, Alpaslan G, Çakır M. Clinical and radiographic evaluation of the efficacy of platelet-rich plasma combined with hydroxyapatite bone graft substitutes in the treatment of intra-bony defects in maxillofacial region. Acta Odontol Scand. 2014;72(8):948-953. doi: 10.3109/00016357.2014.926023.

10. Ahmed M, Salah MK, Khairy N. Computer-aided design/computer-aided manufacturing cutting guides for odontectomy of deeply impacted mandibular third molars. Open Access Maced J Med Sci. 2018;6(12):2395-2401. doi: 10.3889/ oamjms.2018.371.

11. Kutkut A, Andreana S, Kim HL, Monaco E Jr. Extraction socket preservation graft before implant placement with calcium sulfate hemihydrate and platelet-rich plasma: a clinical and histomorphometric study in humans. J Periodontol. 2012;83(4):401-409. doi: 10.1902/jop.2011.110237.

12. Antonello Gde M, Torres do Couto R, Giongo CC, Corrêa MB, Chagas Júnior OL, Lemes CH. Evaluation of the effects of the use of platelet-rich plas$\mathrm{ma}(\mathrm{PRP})$ on alveolar bone repair following extraction of impacted third molars: prospective study. J Craniomaxillofac Surg. 2013;41(4):e70-e75. doi: 10.1016/j.jcms.2012.11.003.

13. Célio-Mariano R, de Melo WM, Carneiro-Avelino C. Comparative radiographic evaluation of alveolar bone healing associated with autologous plateletrich plasma after impacted mandibular third molar surgery. J Oral Maxillofac Surg. 2012;70(1):19-24. doi: 10.1016/j.joms.2011.03.028.

14. Ogundipe OK, Ugboko VI, Owotade FJ. Can autologous platelet-rich plasma gel enhance healing af- 
ter surgical extraction of mandibular third molars? J Oral Maxillofac Surg. 2011;69(9):2305-2310. doi: 10.1016/j.joms.2011.02.014.

15. He Y, Chen J, Huang Y, Pan Q, Nie M. Local application of platelet-rich fibrin during lower third molar extraction improves treatment outcomes. J Oral Maxillofac Surg. 2017;75(12):2497-2506. doi: 10.1016/j.joms.2017.05.034.

16. Canellas JVDS, Ritto FG, Medeiros PJD. Evaluation of postoperative complications after mandibular third molar surgery with the use of platelet-rich fibrin: a systematic review and meta-analysis. Int J Oral Maxillofac Surg. 2017;46(9):1138-1146. doi: 10.1016/j.ijom.2017.04.006.

17. Varghese MP, Manuel S, Kumar LKS. Potential for osseous regeneration of platelet-rich fibrin - a comparative study in mandibular third molar impaction sockets. J Oral Maxillofac Surg. 2017;75(7):1322-1329. doi: 10.1016/j. joms.2017.01.035.

18. Kumar N, Prasad K, Ramanujam L, K R, Dexith J, Chauhan A. Evaluation of treatment outcome after impacted mandibular third molar surgery with the use of autologous platelet-rich fibrin: a randomized controlled clinical study. J Oral Maxillofac Surg. 2015;73(6):1042-1049. doi: 10.1016/j. joms.2014.11.013.

19. Tamiolakis P, Thermos G, Tosios KI, SklavounouAndrikopoulou A. Demographic and clinical characteristics of 5294 jaw cysts: a Retrospective study of 38 years. Head Neck Pathol. 2019 Feb 13. doi: 10.1007/s12105-019-01011-7.

20. Chen JH, Tseng CH, Wang WC, Chen CY, Chuang FH, Chen YK. Clinicopathological analysis of 232 radicular cysts of the jawbone in a population of southern Taiwanese patients. Kaohsiung J Med Sci. 2018;34(4):249-254. doi: 10.1016/j.kjms.2018.01.011.

21. Mello FW, Melo G, Kammer PV, Speight PM, Rivero ERC. Prevalence of odontogenic cysts and tumors associated with impacted third molars: A systematic review and meta-analysis. J Craniomaxillofac Surg. 2019;47(6):996-1002. doi: 10.1016/j. jcms.2019.03.026.

22. da Silva LP, Serpa MS, Sobral APV, Arruda JAA, Silva LVO, Noronha MS, et al. A retrospective multicentre study of cystic lesions and odontogenic tumours in older people. Gerodontology. 2018;35(4):325-332. doi: 10.1111/ger.12354.
23. da Silva LP, Gonzaga AK, Severo ML, Barros CC, de Medeiros AM, de Souza LB, et al. Epidemiologic study of odontogenic and non-odontogenic cysts in children and adolescents of a Brazilian population. Med Oral Patol Oral Cir Bucal. 2018a;23(1):e49e53. doi: 10.4317/medoral.22138.

24. Kilinc A, Gundogdu B, Saruhan N, Yalcin E, Ertas U, Urvasizoglu G. Odontogenic and nonodontogenic cysts: An analysis of 526 cases in Turkey. Niger J Clin Pract. 2017;20(7):879-883. doi: 10.4103/1119-3077.212448.

25. Nakkeeran KP, Saravanan K, Babu P, John RR. Evaluation of bone regeneration in periapical osseous defects with and without platelet rich plasma, combined calcium sulfate and autologous bone graft - A comparative study. J Stomatol Oral Maxillofac Surg. 2019;120(3):196-202. doi: 10.1016/j. jormas.2018.11.008.

26. Ulusoy AT, Turedi I, Cimen M, Cehreli ZC. Evaluation of blood clot, platelet-rich plasma, plateletrich fibrin, and platelet pellet as scaffolds in regenerative endodontic treatment: A prospective randomized trial. J Endod. 2019;45(5):560-566. doi: 10.1016/j.joen.2019.02.002.

27. Shah N, Cairns M. Autologous platelet concentrates to improve post extraction outcomes. Evid Based Dent. 2018;19(4):118-119. doi: 10.1038/ sj.ebd.6401347.

28. Murray PE. Platelet-rich plasma and platelet-rich fibrin can induce apical closure more frequently than blood-clot revascularization for the regeneration of immature permanent teeth: a meta-analysis of clinical efficacy. Front Bioeng Biotechnol. 2018;6:139. doi: 10.3389/fbioe.2018.00139.

29. Arenaz-Búa J, Luaces-Rey R, Sironvalle-Soliva S, Otero-Rico A, Charro-Huerga E, Patiño-Seijas B, et al. A comparative study of platelet-rich plasma, hydroxyapatite, demineralized bone matrix and autologous bone to promote bone regeneration after mandibular impacted third molar extraction. Med Oral Patol Oral Cir Bucal. 2010;15(3):e483-e489.

30. Singh M, Bhate K, Kulkarni D, Santhosh Kumar SN, Kathariya R. The effect of alloplastic bone graft and absorbable gelatin sponge in prevention of periodontal defects on the distal aspect of mandibular second molars, after surgical removal of impacted mandibular third molar: a comparative prospective study. J Maxillofac Oral Surg. 2015;14(1):101-106. doi: 10.1007/s12663-013-0599-Z. 
31. Tsai SJ, Chen MH, Lin HY, Lin CP, Chang HH. Pure type-1 collagen application to third molar extraction socket reduces postoperative pain score and duration and promotes socket bone healing. J Formos Med Assoc. 2019;118(1 Pt 3):481-487. doi: 10.1016/j.jfma.2018.08.003.

32. Kilinc A, Ataol M. How effective is collagen resorbable membrane placement after partially impacted mandibular third molar surgery on postoperative morbidity? A prospective randomized comparative study. BMC Oral Health. 2017;17(1):126. doi: 10.1186/s12903-017-0416-Z.

33. Cortell-Ballester I, Figueiredo R, Valmaseda-Castellón E, Gay-Escoda C. Effects of collagen resorbable membrane placement after the surgical extraction of impacted lower third molars. J Oral Maxillofac Surg. 2015;73(8):1457-1464. doi: 10.1016/j. joms.2015.02.015.
34. Dhote VS, Thosar NR, Baliga SM, Dharnadhikari P, Bhatiya P, Fulzele P. Surgical management of large radicular cyst associated with mandibular deciduous molar using platelet-rich fibrin augmentation: a rare case report. Contemp Clin Dent. 2017;8(4):647-649. doi: 10.4103/ccd.ccd_370_17.

35. Georgiev T, Edrev S. Clinical case of filling material forced in the mandibular canal (clinical case and treatment). J IMAB. 2010;16(4):38-40. doi: 10.5272/ jimab.1642010_38-40. 